\title{
Integration of Fuels Types and Chemical Properties with the Design of the Rocket Engine's Bell Exhaust Nozzle and Combustion Chamber
}

\author{
CATALIN NAE ${ }^{1}$, IRINA-CARMEN ANDREI ${ }^{1}$, GABRIELA-LILIANA STROE ${ }^{2 *}$, SORIN BERBENTE ${ }^{1,2}$ \\ ${ }^{1}$ INCAS - National Institute for Aerospace Research "Elie Carafoli”, 220 Iuliu Maniu Blvd., 061126, Bucharest, Romania \\ andrei.irina@incas.ro, icandrei28178@gmail.com, \\ ${ }^{2}$ Politehnica University of Bucharest, Faculty of Aerospace Engineering, 1-7 Gh. Polizu Str., 011061, Bucharest, Romania
}

\begin{abstract}
The chemical properties of the fuels are crucial for obtaining the numerical accuracy during the design and performance analysis in case of liquid fuel propelled rocket engines, as well as the trajectory optimization. In this paper, the research was primarly focused on optimizing the numerical accuracy for non-linear two-dimensional approximation the Fuel Combustion Charts; secondarily, the investigation was carried on the design of the bell-nozzle of a liquid propelled rocket engine, taking into account the variation of the coefficients which are significant for expressing the fuels chemical properties. From the Fuel Combustion Charts, the authors selected a the LOX - Kerosene combination for propelling the rocket engine, due to the most convenient matching with the technology and material specifications, safety and environmental friendly requirements; from the LOX-Kerosene Charts, the authors have originally developed a method to obtain the expression of a non-linear approximation function of two variables. The design of the bell shaped nozzle and combustion chamber for a liquid propelled rocket engine was included, in purpose to illustrate the link between the LPRE design and the fuels types and chemical properties.
\end{abstract}

Keywords: fuel combustion charts, liquid propelled rocket engines, combustion chambers

The design and performance analysis of jet engines and rocket engines require appropriate mathematical modeling for complex intricate phenomena; the main goal is the obtaining of the best numerical accuracy. The algorithms and input data can be validated in experiment and comparison with available data from state of art survey.

Relevant to this topic, can be approached investigations for complex and intricate phenomena, such as: propellant atomization, mixing, evaporation, chemical reaction, gas expansion, as well as effects (e.g. chemical reaction rates, and boundary-layer and streamline and velocity-vector divergence in the converging and diverging nozzles) intended to a more accurate description of real phenomena.

As potential fuels for liquid-propelled rocket engines can be considered the following: Liquid Oxygen-LOX as oxidizer and Kerosene (n-Dodecane, $\mathrm{C}_{12} \mathrm{H}_{26}$ ), LOX-Liquid Hydrogen, Liquid Methane $\mathrm{CH}_{4}$ and Ethyl Alcohol $\mathrm{CH}_{3} \mathrm{CH}_{2} \mathrm{OH}$, LOX-UDMH (1,1 - dimethylhydrazine), Red-Fuming Nitric Acid - Kerosene, Red - Fuming Nitric Acid - MMH (Monomethylhydrazine, $\mathrm{CH}_{3} \mathrm{~N}_{2} \mathrm{H}_{3}$ ), Red-Fuming Nitric Acid - UDMH (1,1 - dimethylhydrazine), Nitrogen Tetroxide-MMH (Monomethylhydrazine, $\mathrm{CH}_{3} \mathrm{~N}_{2} \mathrm{H}_{3}$ ), Nitrogen Tetroxide-Aerozine 50, Hydrogen Peroxide-Kerosene.

Taking into account significant design criteria, such as: minimizing costs, enhancing operational safety, more environmental friendly, from all the above mentioned combinations, there are best fit: Liquid Oxygen - LOX as oxidizer and Kerosene $\mathrm{C}_{12} \mathrm{H}_{26}$, Liquid Methane $\mathrm{CH}_{4}$ and Ethyl Alcohol $\mathrm{CH}_{3} \mathrm{CH}_{2} \mathrm{OH}$.

\section{Experimental part}

The experimental data obtained by Aerojet Rocketdyne (which was previously known as Pratt \& Whitney Rocketdyne, during 2005-2013, and before that, as Rocketdyne Division) were concluded such as to express the performances of rocket propellant combinations, [Huzel].

The JANNAF Rocket Engine Perormance Prediction and Evaluation Manual [ JANNAF ], gives thorough information regarding the mathematical algorithms customized for numerical simulations of all types of jet propelled engines. Relevant to this topic, can be approached investigations for complex and intricate phenomena, such as:

\footnotetext{
*email: ing.stroe@yahoo.com
} 
propellant atomization, mixing, evaporation, chemical reaction, gas expansion, as well as effects (e.g. chemical reaction rates, and boundary-layer and streamline and velocity-vector divergence in the converging and diverging nozzles) intended to a more accurate description of real phenomena.

Thrust evaluation or thrust prediction at different flight regimes, as well as the analysis of flight dynamics, trajectory optimization are important tasks for both the design and performance analysis of liquid propelled rocket engines; in such context, of crucial interest are the Propellant Combustion Charts, Braeunig, 2005 [1], which provide graphically the correlations between the chamber pressure $p_{c}$, exit pressure conditions $p_{e}$ (i.e. burned gas expelled at ambient pressure or in vacuum) and mixture ratio $r$ (which expresses the ratio of Oxygen to Fuel $\mathrm{O} / \mathrm{F}$ ), adiabatic flame temperature $T_{c}$ (also referred as the Chamber Temperature), gas molecular weight $M_{w}$ and specific heat ratio $\gamma$, (also referred as the adiabatic power coefficient), for different types and combinations of fuel and oxidizer, Braeunig [1].

The research presented in this paper is focused on the LOX - Kerosene combination, with the consideration of the LOX - Kerosene Charts (Liquid Oxygen and Kerosene (n-Dodecane, $C_{12} H_{26}$ )), which are shown in Fig. $1 \div$ Fig. 4; [1].

The importance of the Propellant Combustion Charts consists in the fact that enables the realistic and accurate prediction of the rocket engines global on- and off-design performances.

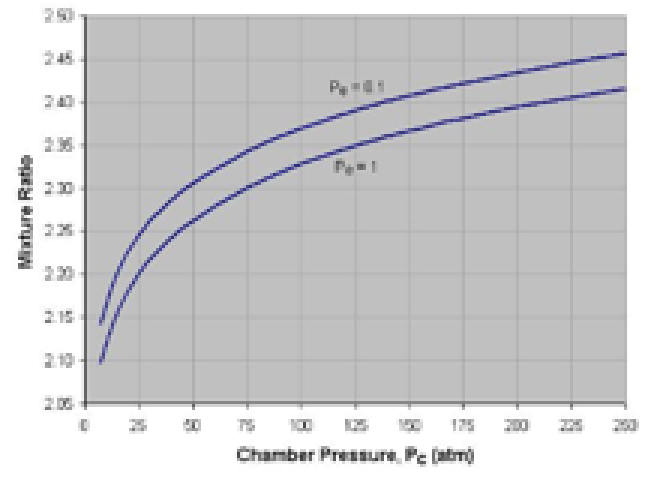

Fig. 1.Optimum mixture ratio, LOX-K, [1]

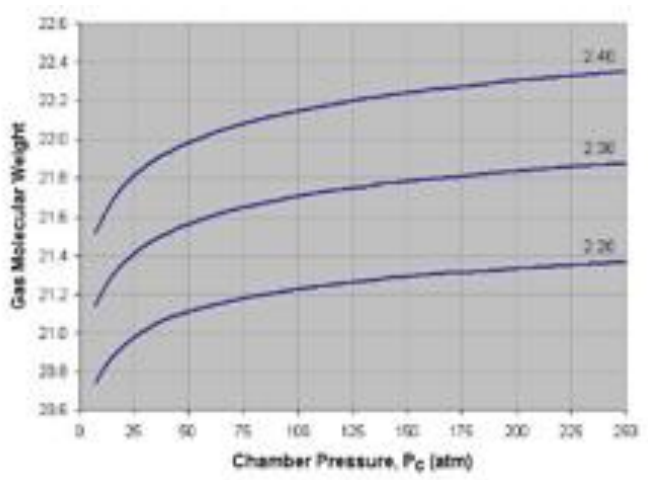

Fig. 3. Gas Molecular Weight, LOX-K, [1]

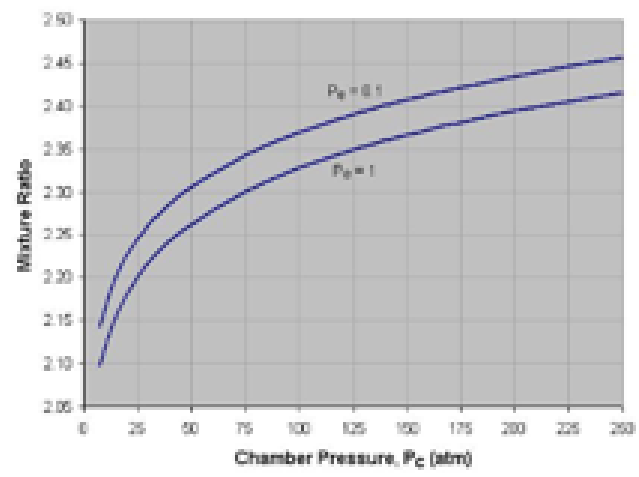

Fig. 2. Adiabatic flame temperature, LOX-K, [1]

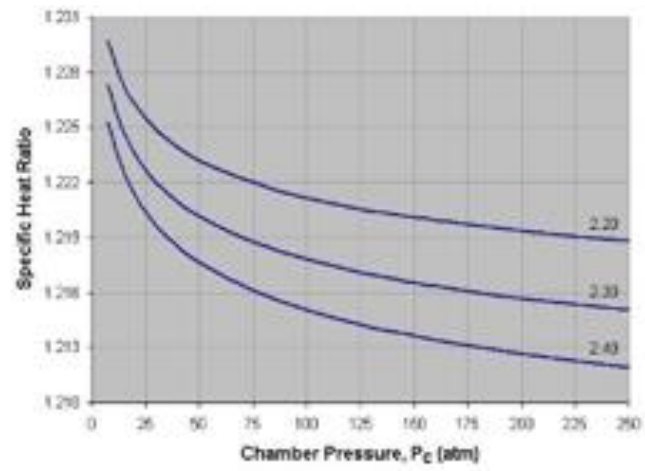

Fig. 4.Secific Heat Ratio, LOX-K, [1]

\section{Results and discussions}

For the development of efficient codes and their optimization, the Fuel Combustion Charts must be frequently called. For processing a large amount of data, a significant reduction of the computation time can be obtained by replacing the nodal read input sequnces with the call of an unique two-dimensional non-linear approximation function.

In this paper is presented an original approach Andrei I. [4] in order to determine a 2D non-linear approximation function, of two variables: the chamber pressure and the nozzle exit pressure ratio.

The numerical algorithm based on this two variable approximation function is more efficient due to its simplicity, capability to providing numerical accuracy and prospects for increased convergence rate of the optimization codes. 

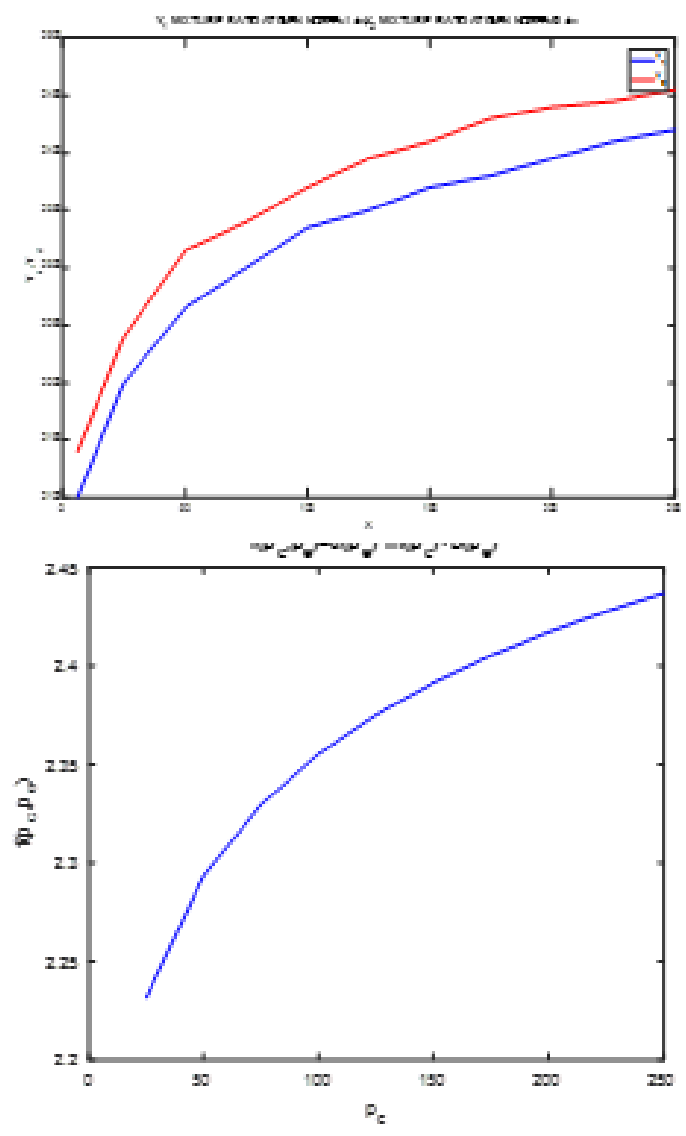

Fig. 5. Mixture ratio versus pressure chamber, for given pressure exit: a) 1 [atm], b) 0.1 [atm]

Fig. 6. 2D non-linear approximation function for mixture ratio versus pressure chamber, and nozzle pressure exit: a) 1 [atm], b) 0.1 [atm]

The first step of the proposed methodology, Andrei I. [4] is completed by the determination of the non-linear single variable approximation functions, Berbente [8], Hure \& Pelat [9], Jedrzejewsky [10], Chapra [11], Press, Teukolsky, Vetterking \& Flannery [12], Chasnov [13], which are verified and shown graphically in Fig. 5; in blue contour is the non-linear approximation determined for the nozzle exit pressure $=1[\mathrm{~atm}]$, and in red contour is the one corresponding to the nozzle exit pressure $=0.1[\mathrm{~atm}]$.

Basically, for determining the non-linear single variable approximation functions, Andrei I. [4], has been used a nonlinear curve fitting instead of linear regression, Andrei I. [13-14], thus being provided an improved numerical accuracy for the least squares approximation method, Andrei I. [4, 13-14].

The nozzle exit pressure is considered as given constant, while the chamber pressure is an input variable.

The second step consists in determining the non-linear two-variable approximation function (1), Andrei I. [4], as shown in Fig. 6 and its verification. In this case, both nozzle exit pressure and chamber pressure are input variables.

$$
f\left(p_{c}, p_{e}\right)=a\left(p_{e}\right) \ln \left(p_{c}\right)+b\left(p_{e}\right)
$$

The new function (1), Andrei I. [4] can generate all the values for the mixture ratio, for all combinations of the two variables: chamber pressure and nozzle exit pressure. The most important advantage provided by the new expression for the 2D non-linear approximation function (1) consists in the fact that it can be used in a very simple manner for all the variations ilustrated in Fig. 1-Fig. 4, for all types of propellants, which are presented in the Propellant Combustion Charts [1].

From practical use, errors in reading input data from given graphics (e.g. Fig. 1-Fig.4), can occur, Fig. 5. But, another important advantage of the new function (1) consists in smoothing the errors introduced when reading input data from given graphics, thus the numerical accuracy being successfully improved.

Since the liquid propelled rocket engine LPRE is a very complex product, its adequate design requires succesive iterations and further optimization. The most important is the aero-thermodynamic analysis, with a focus on sizing the exhaust nozzle and the combustion chamber.

Next, the aero-thermodynamic analysis will continue on two basic directions:

1)- determining the performances (i.e. engine thrust) for the liquid propelled rocket engine LPRE for the design regime and for all off-design regimes, Huzel \& Huang [2], Sutton \& Biblarz [3];

2)- engine control and throttleability, Sutton \& Biblarz [3], Casiano, Hulka \& Yang [7]. 


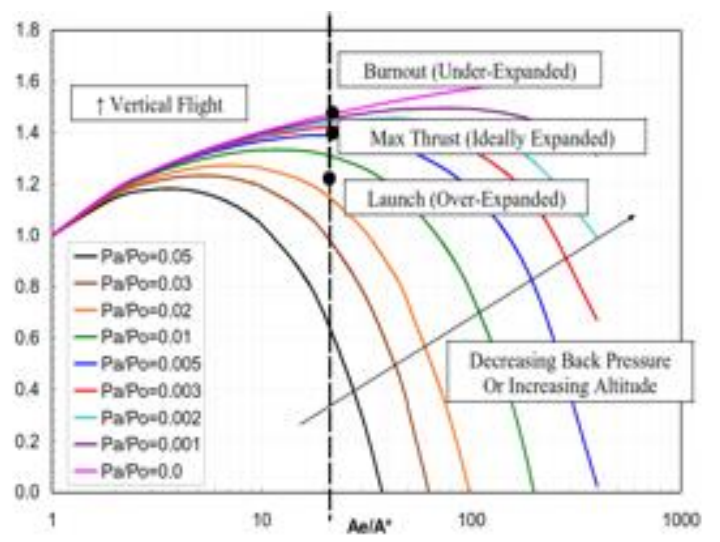

Fig. 7. Correlations between geometrical parameters of LPRE with Bell nozzle and operational conditions of the flight and aerothermodynamical parameters

From the standpoint of LP rocket engine control, the controllable physical parameters of the rocket engine are, Huzel \& Huang [2], Sutton \& Biblarz [3], Casiano, Hulka \& Yang [7]:

- Propellant flow rates,

- Propellant types, composition and the chemical properties,

- Nozzle exit area,

- Nozzle throat area.

The Throttling Critical Issues are:

- Combustion and system instabilities

- Performance degradation

- Excessive heat transfer

- Pump dynamics.

The geometrical solution following the iterative design of the liquid propelled rocket engine LPRE is successively improved Huzel \& Huang [2], Sutton \& Biblarz [3], after investigating operational conditions of the flight, in correlation with the vehicle flight dynamics, Balesdent [5-6].

Fig.ure 7 illustrates the correlation between the ratio of nozzle exit area $A_{e}$ to throat area $A^{*}$ and ratio of ambient pressure to nozzle exit pressure.

The liquid propelled rocket engine LPRE can be designed Huzel \& Huang [2], Sutton \& Biblarz [3], with different types of nozzles; the most used are the conical nozzle (due to its simplicity construction, technology solution, manufacturing and maintenance) and the Bell shaped nozzle (which can be further optimized for a better adaptability to the operational conditions, with minimal pressure losses, due to shock wave interaction, boundary layer separation and/ or re-attachment.

In Figure 8 are detailed the geometrical parameters of the Bell nozzle.

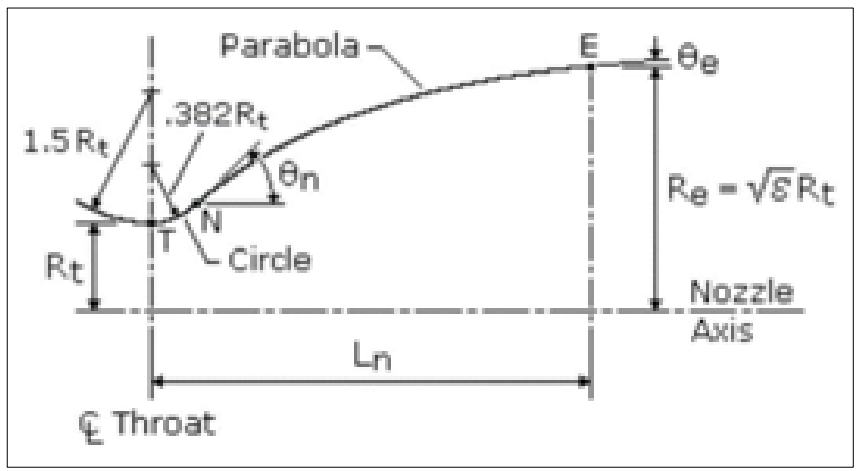

Fig. 8.Geometrical parameters of Bell nozzle [2]

The design of the main parts of the liquid propelled rocket engine LPRE, i.e. the combustion chamber and the nozzle is influenced in great extent by the fluid types considered to cross the engine, which involve different values in sizing the length of both the chamber and the nozzle.

Following a current state of art, it was highlighted significant variation of the combustion chamber characteristic length, Huzel \& Huang [2] with the consideration of the propellant combination, as listed in Table 1. 
Table 1

CORRELATION BETWEEN LIQUID PROPELLED ROCKET

ENGINE FUELS TYPESAND THE CHAMBER CHARACTERISTIC LENGTH, HUZEL \& HUANG [2]

\begin{tabular}{|c|c|}
\hline Propellant combination & $\mathrm{L}^{*}[\mathrm{~cm}]$ \\
\hline Nitric acid/ hydrazine-base fuel & $76-89$ \\
\hline Nitrogen tetroxide / hydrazine-base fuel & $76-89$ \\
\hline $\begin{array}{c}\text { Hydrogen peroxide / RP-1 (including } \\
\text { catalyst bed) }\end{array}$ & $152-178$ \\
\hline Liquid oxygen / RP -1 & $102-127$ \\
\hline Liquid oxygen / ammonia & $76-102$ \\
\hline $\begin{array}{c}\text { Liquid oxygen / Liquid hydrogen }\left(\mathrm{GH}_{2}\right. \\
\text { injection) }\end{array}$ & $56-71$ \\
\hline $\begin{array}{c}\text { Liquid oxygen / Liquid hydrogen }\left(\mathrm{LH}_{2}\right. \\
\text { injection) }\end{array}$ & $76-102$ \\
\hline $\begin{array}{c}\text { Liquid fluorine / Liquid hydrogen }\left(\mathrm{GH}_{2}\right. \\
\text { injection) }\end{array}$ & $56-66$ \\
\hline $\begin{array}{c}\text { Liquid fluorine / Liquid hydrogen ( } \mathrm{LH}_{2} \\
\text { injection) }\end{array}$ & $64-76$ \\
\hline Liquid fluorine / hydrazine & $61-71$ \\
\hline Chlorine trifluoride / hydrazine-base fuel & $51-89$ \\
\hline
\end{tabular}

A relevant example considered to support this study is the application consisting in the design of a Bell exhaust nozzle for a liquid propelled rocket engine LPRE, with the propellant combination Liquid oxygen / RP -1, intended to develop at design regime the thrust (2), (2.1) and the ratio (3) of exhaust nozzle area to throat area being (3.1):

$$
\begin{gathered}
F_{T}=\dot{m} v_{e}+\left(p_{e}-p_{a}\right) A_{e} \\
F_{T}=2000[N] \\
\varepsilon=\frac{A_{e}}{A^{*}} \\
\varepsilon=20
\end{gathered}
$$

Other input data are: the propellant flow rate $q=0.615[\mathrm{~kg} / \mathrm{s}]$, the chamber pressure $p_{c}=25[\mathrm{bar}]$, exit velocity $V_{e}=3.251[\mathrm{~km} / \mathrm{s}]$ at operating altitude $H=20[\mathrm{~km}]$.

The engine considered for this study is of type pressure-fed cycle, because this architecture represents the system with simplest construction, since it does not have pumps or turbines, but instead relies on tank pressure to feed the propellants into the main chamber. In practice, the cycle is limited to relatively low chamber pressures because higher pressures make the vehicle tanks too heavy. The cycle can be reliable, given its reduced part count and complexity compared with other systems.

The optimization of engine thrust (2) is carried on according to the balance the nozzle exit pressure $p_{e}$ and the ambient pressure $p_{a}$; the altitude ranges from 0 up to $20[\mathrm{~km}]$, where the ambient pressure is low, $p_{a}=0.0432$ [bar].

The Bell shape nozzle is functionally efficient, due to the fact that allows to minimize or to avoid the boundary layer separation; the Bell nozzles can be further improved by shortening their length to $80 \%$, thus reducing the weight and global dimensions, without the damaging the aerodynamic properties of the LPRE.

From the Propellant Combustion Charts [1], for the propellant type: Liquid Oxygene (LOX) and kerosene (RP-1), resulted the following: combustion temperature $T_{c}=3470[\mathrm{~K}]$, which ranges from 2500 up to 3600 [K], molecular weight for the oxygene $=21.4[\mathrm{~kg} / \mathrm{kmol}]$, specific heat ratio $k=1.221$, and chamber pressure $p_{c}$, usually ranging from 7 up to 250 [bar], but restricted up to 50 [bar], in case of pressure-fed cycle LPRE.

Nozzle sizing satisfyies the condition (4) for thrust (2) optimization at operating altitude, meaning that the nozzle exit pressure $p_{e}$ should match the ambient pressure $p_{a}$. Other situations are the underexpanded nozzle, specified by the condition (5) and the overexpanded nozzle, given by condition (6):

$$
\begin{aligned}
& p_{e}=p_{a} \\
& p_{e}<p_{a}
\end{aligned}
$$




$$
p_{e}>p_{a}
$$

The thrust optimization supposes the determination of the optimal values of the chamber pressure, which results from the calculations performed for different values considered for the chamber pressure:

$$
p_{c} \in\{7,10,20,30,40,50\} \text { [bar]. }
$$

Other connecting results:

The controlling pressure ratio:

$$
\frac{p_{e}}{p_{c}}=\frac{p_{a}}{p_{c}}=\frac{0.00432}{20}=0.00216
$$

The ratio of throat area to exit area:

$$
\begin{aligned}
& \frac{A_{t}}{A_{e}}=\left(\frac{k+1}{2}\right)^{\frac{1}{k-1}} \cdot\left(\frac{p_{e}}{p_{c}}\right)^{\frac{1}{k}} . \\
& \sqrt{\left[\frac{k+1}{k-1}\right] \cdot\left[1-\frac{p_{e}}{p_{c}}\right]^{\left[\frac{k+1}{k}\right]}} \\
& \frac{A_{t}}{A_{e}}=0.03209
\end{aligned}
$$

Throat temperature $T_{t}=3154.5[K]$

$$
T_{t}=\left[\frac{2}{k+1}\right] T_{C}
$$

Throat pressure $p_{t}=11.289479[\mathrm{bar}]$

$$
p_{t}=p_{t} \cdot\left[\frac{k+1}{2}\right]^{\left[-\left[\frac{k}{k-1}\right]\right]}
$$

Ideal exit velocity $V_{e}=3218.944 \cong 3219\left[\frac{\mathrm{m}}{\mathrm{s}}\right]=3.219\left[\frac{\mathrm{km}}{\mathrm{s}}\right]$

$$
\sqrt{2 \cdot\left[\frac{k}{k-1}\right] \cdot R \cdot T_{c}\left[1-\frac{p_{e}}{p_{c}}\right]^{\left[\frac{k-1}{k}\right]}}
$$

where:

- $\quad \mathcal{R}=8314.4621[\mathrm{~J} / \mathrm{kmolK}]$ is the universal gas constant

- $\quad \mathrm{R}(13)$ is the gas constant for the fuel: RP-1 (kerosene)

- $\mathcal{M}=388.5[\mathrm{~kg} / \mathrm{kmol}]$ is the molecular weight for kerosene;

$$
R=\frac{\mathcal{R}}{\mathcal{M}}
$$

Equivalent velocity: $c[\mathrm{~m} / \mathrm{s}], c=V_{e}$.

Specific impulse: $I_{s p}[\mathrm{~s}]$ :

$$
\begin{aligned}
I_{s p} & =\frac{c}{g_{0}} \\
I_{s p} & =328.41[s]
\end{aligned}
$$

The gravitational acceleration is (15): 


$$
g_{0}=9.80665\left[\mathrm{~m} / \mathrm{s}^{2}\right]
$$

Rate of mass ejected $q[\mathrm{~kg} / \mathrm{s}](16)$

$$
\begin{aligned}
& q=\frac{F_{T}}{c} \\
& q=\frac{F_{T}}{c}=\frac{2000}{3219}=0.621311
\end{aligned}
$$

Throat area $A_{t}\left[m^{2}\right](17)$

$$
A_{t}=\left(\frac{q}{p_{c} \cdot 10^{5}}\right) \cdot \sqrt{\frac{\left(R \cdot T_{c}\right)}{\left[k \cdot\left[\frac{2}{k+1}\right]^{\left.\frac{k+1}{k-1}\right]}\right]}}
$$

Exit area $A_{e}\left[m^{2}\right](18)$ is obtained from the throat to nozzle exit area ratio $\varepsilon$ and the throat area $A_{t}$ :

$$
A_{e}=\frac{A_{t}}{\varepsilon}
$$

Throat diameter (19) and nozzle exit diameter (20):

$$
\begin{aligned}
& d_{t}=\sqrt{\frac{4 \cdot A_{t}}{\pi}} \\
& d_{e}=\sqrt{\frac{4 \cdot A_{e}}{\pi}}
\end{aligned}
$$

As a verification, the ratio $\varepsilon(21)$ is the square of exit radius to throat radius ratio, (21); then, the iterative process is resumed, from a recalculating the pressure chamber.

$$
\varepsilon=\left(\frac{d_{e}}{d_{t}}\right)^{2}
$$

The results of the calculations are concluded by the design of the bell shaped nozzle and combustion chamber, illustrated in Figure 9.

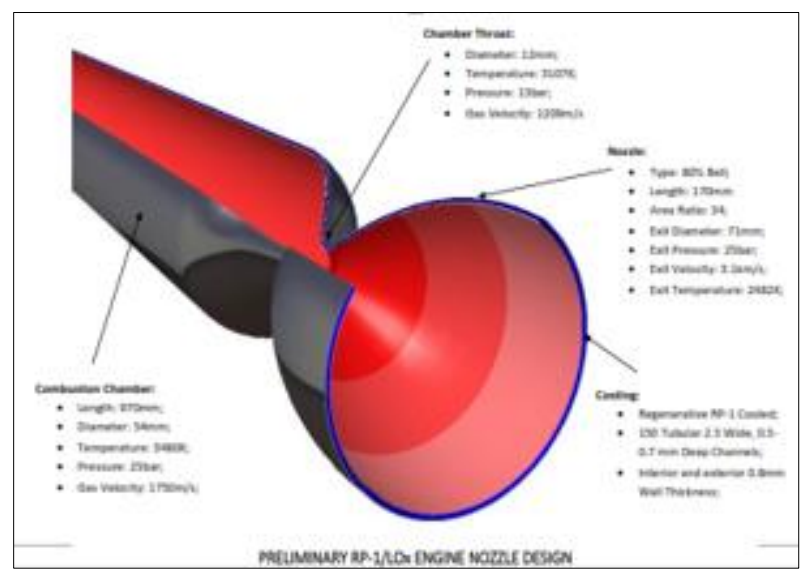

Fig. 9. Geometrical parameters of Bell nozzle [2] 
An example of liquid propellant rocket engine LPRE design is summarized in Tables 2, 3 and 4.

Table 2

RESULTS FROM THE DESIGN OF A LIQUID PROPELLED ROCKET ENGINE LPRE

\begin{tabular}{|c|c|c|}
\hline Parameter & Units IS & Value \\
\hline Thrust & $\mathrm{N}$ & 2000 \\
\hline Time of burning & $\mathrm{s}$ & 302 \\
\hline $\begin{array}{c}\text { Operational altitude } \\
\text { aelocity at operational } \\
\text { altitude }\end{array}$ & $\mathrm{km}$ & 20 \\
\hline Propellant & \multicolumn{2}{|c|}{$\begin{array}{c}\text { Kerosene } \\
\text { (RP-1) }\end{array}$} \\
\hline Oxidizer & \multicolumn{2}{|c|}{$\begin{array}{c}\text { Liquid Oxygene } \\
\text { (LOX) }\end{array}$} \\
\hline $\begin{array}{c}\text { Combustion chamber } \\
\text { pressure }\end{array}$ & Bar & 25 \\
\hline Mixture ratio & ---- & 2.35 \\
\hline $\begin{array}{c}\text { Combustion chamber } \\
\text { Temperature }\end{array}$ & $\mathrm{K}$ & 3470 \\
\hline Specific Impulse & $\mathrm{s}$ & 331.6 \\
\hline Propellant Mass Flow & $\mathrm{Kg} / \mathrm{s}$ & 0.184 \\
\hline Oxidizer Mass Flow & $\mathrm{Kg} / \mathrm{s}$ & 0.431 \\
\hline
\end{tabular}

Table 3

RESULTS FROM THE DESIGN OF THE LPRE EXHAUST NOZZLE (NOZZLE SHAPE $=80 \%$ BELL NOZZLE)

\begin{tabular}{|c|c|c|}
\hline Parameter & Units IS & Value \\
\hline Area ratio & --- & 37.5 \\
\hline Chamber throat diameter & $\mathrm{mm}$ & 24 \\
\hline Nozzle exit diameter & $\mathrm{mm}$ & 145 \\
\hline Nozzle length & $\mathrm{mm}$ & 170 \\
\hline Nozzle exit temperature & $\mathrm{K}$ & 2482 \\
\hline Nozzle exit pressure & $\mathrm{Bar}$ & 0.05 \\
\hline Exhaust velocity & $\mathrm{Km} / \mathrm{s}$ & 3.252 \\
\hline
\end{tabular}

Table 4

RESULTS FROM THE DESIGN OF THE LPRE COMBUSTION CHAMBER

\begin{tabular}{|c|c|c|}
\hline Parameter & Units IS & Value \\
\hline $\begin{array}{c}\text { Combustion chamber } \\
\text { diameter }\end{array}$ & $\mathrm{mm}$ & 24 \\
\hline Chamber length & $\mathrm{mm}$ & 970 \\
\hline Throat temperature & $\mathrm{K}$ & 3155 \\
\hline Throat fluid pressure & $\mathrm{Bar}$ & 13 \\
\hline Throat fluid velocity & $\mathrm{Km} / \mathrm{s}$ & 1.2 \\
\hline
\end{tabular}

\section{Conclusions}

The fuels types and chemical properties have been integrated in the design LPRE, by the means of the following:

-Propellant Combustion Charts, where the molecular weight, ratio of specific heats, mixture ratio, adiabatic flame temperature, have been specified in correlation with the pressure chamber and nozzle exit pressure;

-The new determined function (1) can replace the Propellant Combustion Chart, for all types of fuels and their chemical properties; the major advantage resides in significant reduction of computer time, by calling one twodimensional non-linear function, instead of reading vectors of nodes and calculating at each iteration new spline function;

-For an adequate design and further its optimization, it is necessary to investigate state of art and to use knowledge and databases which present correlations of geometrical parameters, sizes of LPRE parts and types of fuels and their chemical properties, which have been obtained from experiment and previous LPRE design history.

-Further, the integration of fuel types and chemical properties is very important and relevant in determining the thrust and the remaining performances of the LPRE, at the design regime and all off-design regimes; and also, for LPRE control and throttleability, Casiano, Hulka \& Yang [7].

-From the standpoint of LP rocket engine control, from the list of the controllable physical parameters of the liquid propelled rocket engine LPRE, aside the fuel types and chemical properties, the propellant chemical composition plays a major part. 
-The integration of fuel types, chemical properties and composition are very important and their appropriate consideration in monitoring LPRE throttle critical issues, influences the numerical accuracy in large extent.

The shape of the new function can be successfully used to generate all the values for fuel properties, for all the combinations of the two variables, meaning the chamber pressure and nozzle exit pressure. An other significant advantage of the new function consists in the ability to smoothen the errors introduced when reading input data from given graphics, thus the numerical accuracy being improved in a highly extent.

\section{References}

1. ***www.braeunig.us/space/comb/, Rocket and Space Technology, Propellant Combustion Charts.

2. DIETER K. HUZEL, DAVID H. HUANG, NASA SP-125, Design of Liquid Propelled Rocket Engines, Rocketdyne Division, North American Aviation, Inc., Scientific and Technical Information Division, OFFICE OF TECHNOLOGY UTILIZATION NATIONAL AERONAUTICS AND SPACE ADMINISTRATION, Washington, $2^{\text {nd }}$ Edition, 1967.

3. GEORGE SUTTON, OSCAR BIBLARZ, Rocket Propulsion Elements, $8^{\text {th }}$ Edition, John Wiley \& Sons, New Jersey, 2010.

4. IRINA-CARMEN ANDREI, Determination of a Two Variable Approximation Function with Application to the Fuel Combustion Charts, International Workshop on Numerical Modelling in Aerospace Sciences, NMAS 2017,17-18 May 2017, Bucharest, Romania; INCAS Bulletin, September 2017.

5. MATHIEU BALESDENT, Multidisciplinary Design Optimization of Launch Vehicles, Optimization and Control, [math.OC], Ecole Centrale de Nantes (ECN) (ECN) (ECN), 2011, English, HAL Id: tel-00659362, https://tel.archives-ouvertes.fr/tel-00659362, submitted on 12 Jan 2012.

6. LOÏC BREVAULT, MATHIEU BALESDENT, NICOLAS BÉREND, RODOLPHE LE RICHE, Multi-level hierarchical MDO formulation with functional coupling satisfaction under uncertainty, application to sounding rocket design, World Congress on Structural and Multidisciplinary Optimization, 7-12 June 215, Sydney, Australia.

7. MATHEW CASIANO, JAMES HULKA, VIGOR YANG, Liquid Propellant Rocket Engine Throttling: A Comprehensive Review, AIAA 2009-5135, 45 ${ }^{\text {th }}$ AIAA/ ASME/ SAE/ ASEE Joint Propulsion Conference \& Exibit, 2-5 August 2009, Denver, Colorado; Journal of Propulsion and Power, Vol. 26, No. 5 (2010), pp. 897-923.

8. CORNELIU BERBENTE, S. MITRAN, S. ZANCU, Metode Numerice, Editura Tehnica, 1997.

9. JEAN MARC HURE, DIDIER PELAT, Methodes Numeriques, Univ. Paris 7, version 2, Novembre 2002.

10. FRANCK JEDRZEJEWSKY, Introduction aux Methodes Numeriques, deuxieme edition, Springer Verlag, Paris 205, ISBN 978-2-287-252037.

11. STEVEN CHAPRA, Applied Numerical Methods with MATLAB for Engineers and Scientists, Mc Graw Hill, New York, 2012, ISBN 9780-07-340110-2.

12. WILLIAM PRESS, SAUL TEUKOLSKY, WILLIAM VETTERKING, BRIAN FLANNERY, Numerical Recipes in Fortran 77, The Art of Scientific Computing, $2^{\text {nd }}$ Edition, vol. 1, Cambridge University Press, New York, 1992.

13. JEFFREY CHASNOV, Introduction to Numerical Methods, Lecture notes for MATH 3311, The Hong Kong University of Science and Technology, Department of Mathematics, 2012.

14. IRINA CARMEN ANDREI, Methodes Numeriques, Note de curs si Aplicatii Laborator/ Moodle, UPB, FILS, Filiera Franceza, $2006-2012$. 15. IRINA CARMEN ANDREI, Numerische Berechnungsverfahren, Note de curs si Aplicatii Laborator/ Moodle, UPB, FILS, Filiera Germana, 2006-2012.

Manuscript received: 31.07 .2018 